\title{
Fungos micorrízicos arbusculares nativos e doses de fósforo no desenvolvimento do amendoim RUNNER IAC 886 $^{1}$
}

\author{
Native mycorrhizal fungi and phosphate doses in the development of peanut \\ RUNNER IAC 886
}

Franz Walter Rieger Hippler ${ }^{2}$, Milene Moreira ${ }^{3 *}$, Naissa Maria Silvestre Dias $^{4}$ e Emilio Rodolfo Hermann ${ }^{5}$

\begin{abstract}
Resumo - Objetivou-se avaliar a interação entre fungos micorrízicos arbusculares nativos (FMA) com plantas de amendoim (Arachis hypogea) cultivar RUNNER IAC 886, em diferentes doses de fósforo (P). O experimento foi conduzido em casa de vegetação em delineamento inteiramente casualizado, em esquema fatorial ( 2 x 5), sendo com e sem a inoculação dos endófitos e cinco doses de $\mathrm{P}\left(0 ; 20 ; 40 ; 60\right.$ e $180 \mathrm{mg} \mathrm{kg}^{-1}$ na forma de $\left.\mathrm{KH}_{2} \mathrm{PO}_{4}\right)$, com quatro repetições. Avaliaram-se massa seca de: raiz, parte aérea, total, taxa de colonização radicular (CR), dependência micorrízica (DM) e eficiência micorrízica (EM). Concluiuse que as doses crescentes de adubação fosfatada promoveram aumento no desenvolvimento das plantas de amendoim. Os FMA promoveram a produção máxima de massa seca total do amendoim na dose estimada de $114,0 \mathrm{mg} \mathrm{kg}^{-1} \mathrm{de} P$. A maior colonização radicular e eficiência micorrízica foram verificadas na dose $60 \mathrm{mg} \mathrm{kg}^{-1} \mathrm{de}$ P.
\end{abstract}

Palavras-chave - Amendoim. Adubação. Fertilizantes fosfatados. Fungos micorrízicos arbusculares.

\begin{abstract}
The objective was to evaluate the interaction between native arbuscular mycorrhizal fungi (AMF) with peanut plants (Arachis hypogea) RUNNER cultivar IAC 886, at different levels of phosphorus (P). The experiment was conducted in a greenhouse in a randomized design in factorial $(2 \times 5)$, with and without inoculation of AMF and five $\mathrm{P}$ levels $\left(0 ; 20 ; 40 ; 60\right.$ and $180 \mathrm{mg} \mathrm{kg}^{-1}$ in the form of $\left.\mathrm{KH}_{2} \mathrm{PO}_{4}\right)$ in four replications. Shoot, root and total dry mass, root colonization, mycorrhizal dependency and mycorrhizal efficiency were evaluated. It was concluded that increasing levels of phosphorus caused an increase in the development of peanut plants. The AMF promoted maximum production of total dry mass of the peanut in estimated dose of $114.0 \mathrm{mg} \mathrm{kg}^{-1}$ of $\mathrm{P}$. The highest root colonization and mycorrhizal efficiency were observed at $60 \mathrm{mg} \mathrm{kg}^{-1}$ of $\mathrm{P}$.
\end{abstract}

Key words - Peanut. Fertilization. Phosphate fertilizers. Mycorrhizal fungi.

\footnotetext{
* Autor para correspondência

${ }^{1}$ Recebido para publicação em 10/11/2009; aprovado em 11/05/2011

Pesquisa Financiada pela Fundação de Amparo a Pesquisa do Estado de São Paulo (FAPESP)

${ }^{2}$ Programa de Pós-Graduação em Agricultura Tropical e Subtropical do Instituto Agronômico de Campinas, Campinas, SP, Brasil, 13020-902, franznalty@hotmail.com

${ }^{3}$ APTA/DDD, Pólo Médio Paranapanema, Caixa Postal 263, Assis-SP, Brasil, 19.800-970, mmoreira@apta.sp.gov.br

${ }^{4}$ Programa de Pós-Graduação em Biologia na Agricultura e no Ambiente do CENA/USP, Piracicaba-SP, Brasil, 13.416-000, naissasilvestre@ hotmail.com

${ }^{5}$ Departamento de Geociências, Químicas e Tecnologia/ESAPP, Paraguaçu Paulista-SP, Brasil, 19.700-000, erh456@gmail.com
} 


\section{Introdução}

$\mathrm{O}$ amendoim é uma das principais leguminosas cultivadas no Brasil, juntamente com o feijão e a soja. É um produto rico em óleo, proteínas e vitaminas, conhecido e consumido praticamente por todos os países. A cultivar "RUNNER IAC 886 " é de origem americana, apresenta alto potencial produtivo, além de produzir grãos que atendem integralmente aos quesitos para o padrão comercial, o mais difundido no mercado internacional, nos aspectos físicos (tamanho, uniformidade, cor da panícula) e químicos (relação ácidos graxos oléicos/linoléico entre 1,6 e 1,8 em média).

O amendoim como a maioria das plantas, é potencialmente capaz de se associar aos fungos da ordem Glomales (Glomeromycota), estabelecendo uma simbiose mutualista denominada micorriza arbuscular, na qual os fungos micorrízicos arbusculares (FMA) colonizam o sistema radicular, proporcionando melhor absorção de nutrientes do solo, principalmente de fósforo, e recebendo, em troca, fotossintatos produzidos pela planta (SMITH et al., 2003).

O fósforo é um macronutriente essencial, necessário na maioria dos processos metabólicos, sendo sua essencialidade enfatizada por não poder ser substituído por nenhum outro nutriente nos sistemas biológicos. Apesar do grande volume de pesquisas sobre $\mathrm{P}$ e micorrizas em plantas cultivadas, os efeitos desses fatores sobre o amendoim ainda são restritos.

Vários resultados demonstram que a colonização micorrízica e a eficiência micorrízica aumentam com adição de baixos teores de P (MOREIRA et al., 2007; MOREIRA-SOUZA; CARDOSO, 2002), ou pode ser reduzida em altos teores de P (SENA et al., 2004). Assim como o desenvolvimento das plantas também podem ser afetado pelo teor P no solo (COSTA et al., 2005).

Estudos sobre a dependência micorrízica são importantes para se conhecer as respostas das plantas a micorrização, pois essas podem apresentar associações micorrízicas compatíveis ou incompatíveis, de acordo com as variações das condições ambientais, tais como, nível de fósforo, conteúdo de água, $\mathrm{pH}$, salinidade, temperatura, qualidade e intensidade luminosa, entre outras (MEHROTA, 2005).

Outro aspecto relevante é estudar a eficiência dos FMA nativos que além de ser fácil e rápido de se obter esse inóculo puro, seus benefícios têm sido relatados (HAYMAN, 1982; LAMBERT et al., 1980). O uso de inóculo misto, composto por espécies com diferentes estratégias, pode apresentar resultados melhores para plantas hospedeiras e pode, conseqüentemente, ser mais adequado do que a introdução de uma única espécie de fungo (DAFT, 1983).
Com base nesses resultados foi realizado um experimento com o objetivo de avaliar a interação entre FMA nativos com Arachis hypogea, em diferentes doses de P.

\section{Material e métodos}

O experimento foi conduzido em casa de vegetação da APTA/Pólo Médio Paranapanema, Assis, SP, no período de novembro a fevereiro de 2008 , com delineamento inteiramente casualizado, em esquema fatorial $(2 \times 5)$. Os tratamentos constaram de: plantas inoculadas com esporos de FMA nativos e um controle sem FMA x cinco doses de $\mathrm{P}\left(0 ; 20 ; 40 ; 60\right.$ e $180 \mathrm{mg} \mathrm{kg}^{-1}$ na forma de $\left.\mathrm{KH}_{2} \mathrm{PO}_{4}\right)$, com quatro repetições por tratamento.

Para a obtenção do inóculo utilizado nesse experimento, foram montados primeiramente vasos iscas para multiplicação de esporos coletados em áreas de cultivo de amendoim RUNNER IAC 886. Plantas de braquiária (Brachiaria decumbens) foram utilizadas como multiplicadora dos endófitos presentes nas amostras do campo. Após o ciclo da braquiária, foram retiradas $50 \mathrm{~g}$ de solo desses vasos, contendo esporos e propágulos de FMA nativos e esses foram utilizados como inóculo no presente experimento. Nos vasos controles, foram utilizadas a mesma quantidade de solo rizosférico e raízes de plantas de braquiária não micorrizadas.

O substrato utilizado no experimento foi proveniente de uma amostra de solo classificado como Neossolo Quartzarênico (EMBRAPA, 2006) misturado com uma parte de areia de rio lavada $(2: 1)$. O solo foi autoclavado por duas horas a $121^{\circ} \mathrm{C}$. Após a autoclavagem coletou-se uma amostra para a realização da análise química do substrato, que apresentou as seguintes características: $\mathrm{pH}$ em $\mathrm{CaCl}_{2}=5,2 ; \mathrm{P}$ (resina) $=3 \mathrm{mg} \mathrm{dm}^{-3} ; \mathrm{Ca}=11,0 \mathrm{cmol}_{\mathrm{c}} \mathrm{dm}^{-3} ; \mathrm{Mg}^{2}=6 \mathrm{cmol}_{\mathrm{c}} \mathrm{dm}^{-3}$; $\mathrm{K}($ resina $)=1,2 \mathrm{cmol}_{\mathrm{c}} \mathrm{dm}^{-3} \mathrm{e} \mathrm{Al}(\mathrm{KCl})=2 \mathrm{cmol}_{\mathrm{c}} \mathrm{dm}^{-3}$.

Com base nos resultados apresentados na análise química calculou-se a necessidade de calagem(QUAGGIO; GODOY, 1996) elevando o pH para 6,0, e realizou-se a incubação desse substrato por 20 dias. Posteriormente adicionou o P nas doses de 20; 40; 60 e $180 \mathrm{mg} \mathrm{kg}^{-1}$. Após o período de incubação o solo foi colocado em vasos com capacidade de $4 \mathrm{~kg}$ de substrato previamente lavados e esterilizados com hipoclorito de sódio a 5\%.

As sementes de amendoim cultivar RUNNER IAC 886 foram desinfetadas em solução de hipoclorito de sódio a $0,5 \%$ durante cinco minutos, lavadas com água esterilizada e colocadas em um pré-germinador em folhas de papel germiteste esterilizado, por quatro dias. Após a germinação, três sementes pré-germinadas foram 
plantadas por vaso, sendo que vinte dias após o plantio foi realizado o desbaste, deixando somente uma planta por vaso, e adicionado $30 \mathrm{~mL}$ da solução de Hoagland isenta de fósforo. As plantas foram irrigadas com água destilada conforme a necessidade.

No florescimento as plantas foram colhidas e secas em estufa a $60{ }^{\circ} \mathrm{C}$ por $48 \mathrm{~h}$, e em seguida determinou-se a massa seca da parte área (MSPA) e a massa seca de raiz (MSR). Através do somatório da MSPA e MSR, determinou a massa seca total (MStotal).

Para determinação da colonização micorrízica retirou-se uma alíquota das raízes finas das plantas após a secagem. Essas foram reidratadas em água por doze horas, clarificadas com KOH (10\%) e coradas com azul de triptofano em lactoglicerol $0,05 \%$. A taxa de colonização radicular foi realizada pela técnica de interseção dos quadrantes (GIOVANETTI; MOSSE, 1980; PHILLIPS; HAYMAN, 1970). Calculou-se a dependência micorrízica a partir da massa seca total, de acordo com o seguinte: massa seca de plantas micorrizadas menos massa seca de plantas não micorrizadas e multiplicado por 100 (PLENCHETTE et. al., 1983), nas doses de P utilizadas. E determinou-se a eficiência micorrízica, calculada através da expressão: [(MStotal das plantas micorrizadas - Mstotal das plantas não micorrizadas) x 100]/MStotal das plantas controle.

Para normalização da distribuição da variável, os dados de colonização radicular foram transformados para $\operatorname{arc} \operatorname{sen}(\mathrm{x} / 100)^{1 / 2}$. Todas as variáveis foram submetidas à análise de variância e desdobrando-se as interações. Aplicouse o teste de Tukey a 5\% para a comparação das médias e a análise de regressão, para os fatores quantitativos.

\section{Resultados e discussão}

Para o desenvolvimento e produção da massa seca de raiz (MSR), não houve diferença significativa entre os tratamentos, independente da presença ou não de inóculo, ou da dosagem de $\mathrm{P}$ (dados não apresentados).

A inoculação com FMA e a adição de doses crescentes de $\mathrm{P}$, promoveram efeitos significativos sobre a massa seca da parte aérea (MSPA). No geral, os tratamentos obtiveram valores de ordem crescente conforme o aumento na dose de P (FIG.1). Exceto, quando aplicado quatro vezes a dosagem recomendada (180 $\mathrm{mg} \mathrm{kg}^{-1} \mathrm{de} \mathrm{P}$ ), houve pequena redução da MSPA na presença do endófito. Este fato tem sido verificado por vários autores e em situações diversas (SENA et al., 2004; MOREIRA-SOUZA; CARDOSO, 2002). Existe relato na soja, de doses altas de $\mathrm{P}$ terem reduzido a colonização micorrízica, mas não reduziram a MSPA (BRESSAN et al., 2001).
Verificou-se interação significativa entre doses de $\mathrm{P}$ e os tratamentos (com inóculo ou sem inóculo), o tratamento inoculado com os FMA nativos alcançou o ponto máximo de desenvolvimento de MSPA na dose $116 \mathrm{mg} \mathrm{kg}^{-1}$ de $\mathrm{P}$, enquanto no tratamento sem inoculação de FMA o ponto máximo foi atingido na dose $124 \mathrm{mg} \mathrm{kg}^{-1}$ de P (FIG. 1).

Nesse caso, as plantas de amendoim podem ser consideradas micotróficas facultativas, pois responderam tanto à inoculação quanto ao acréscimo de fósforo ao solo. Resultados semelhantes foram obtidos em outras plantas (AGUIAR et al., 2004; CARNEIRO et al., 2004) e em amendoim (BALOTA et al., 2010; SIEVERDING, 1991).

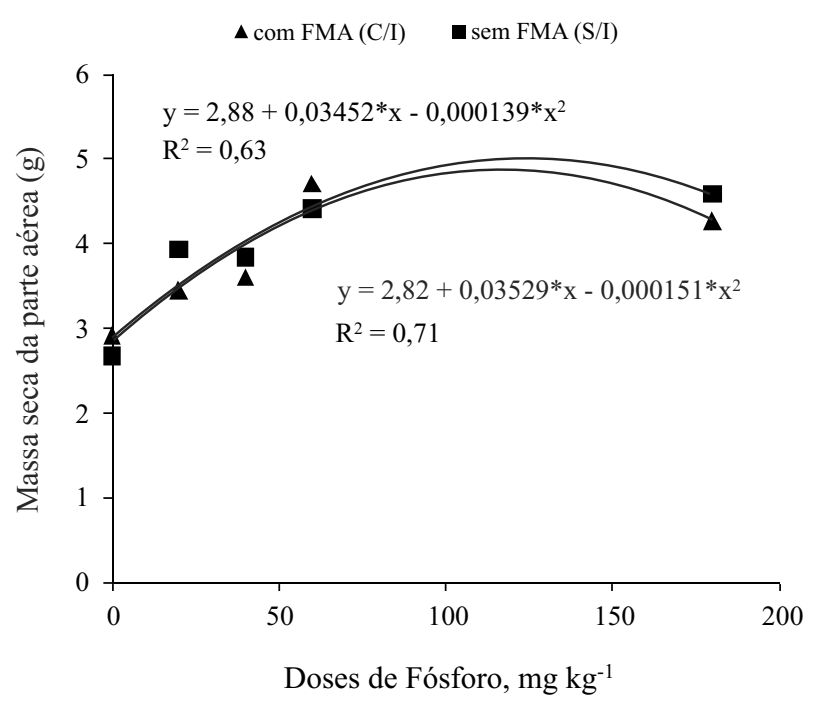

Figura 1 - Massa de matéria seca da parte aérea de plantas de amendoim inoculadas ou não com fungos micorrízicos arbusculares considerando as doses de $\mathrm{P}$.

* Modelos matemáticos de regressão significativos a $1 \%$ pelo Teste F

Quanto à produção de massa seca total houve aumento com as doses crescentes de P, ajustando uma equação quadrática. Para o tratamento com inóculo o ponto de máximo desenvolvimento das plantas de amendoim foi $114,0 \mathrm{mg} \mathrm{kg}^{-1}$ de $\mathrm{P}$ e no tratamento sem inóculo foi em 134,0 $\mathrm{mg} \mathrm{kg}^{-1}$ de P (FIG. 2).

As taxas de colonizações micorrízicas em plantas de amendoim apresentaram diferenças significativas entre as doses de P. Verificou-se que na dose $60 \mathrm{mg} \mathrm{kg}^{-1} \mathrm{de} \mathrm{P}$ ocorreu a maior colonização e a menor foi verificada 
na ausência de P (FIG. 3). Todavia, outro estudo em casa de vegetação adicionando ao solo $0 ; 30 ; 60 ; 120$ e $240 \mathrm{mg} \mathrm{kg}^{-1}$ de $\mathrm{P}$ demonstrou que a colonização radicular do amendoim foi maior na dose $0 \mathrm{mg} \mathrm{kg}^{-1} \mathrm{de}$ $\mathrm{P}$ e decrescendo de acordo com o aumento nas doses de P (BALOTA et al., 2010).

A percentagem de colonização nem sempre é uma característica segura para definir o efeito que o

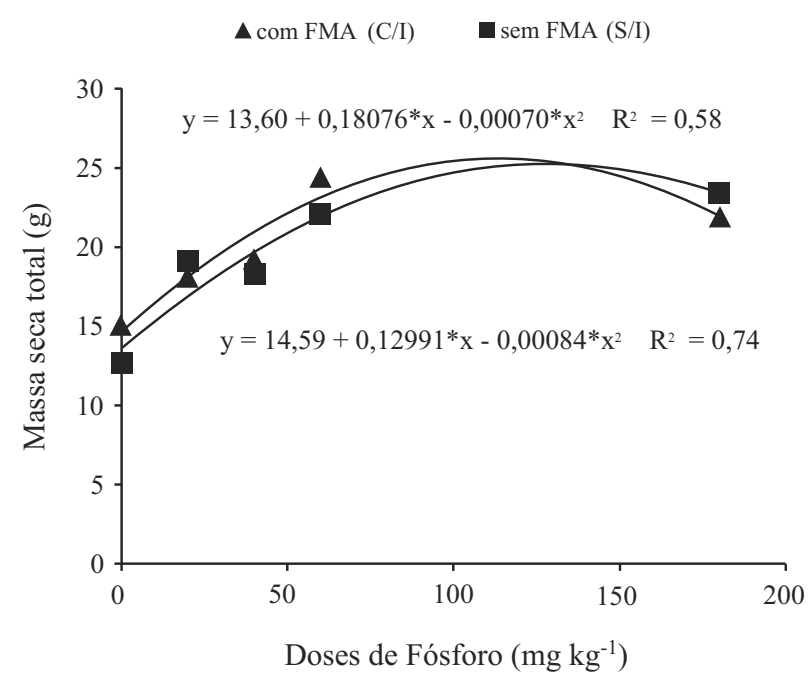

Figura 2 - Massa de matéria seca total de plantas de amendoim inoculadas ou não com fungos micorrízicos arbusculares considerando as doses de P. * Modelos matemáticos de regressão significativos a $1 \%$ pelo Teste $\mathrm{F}$

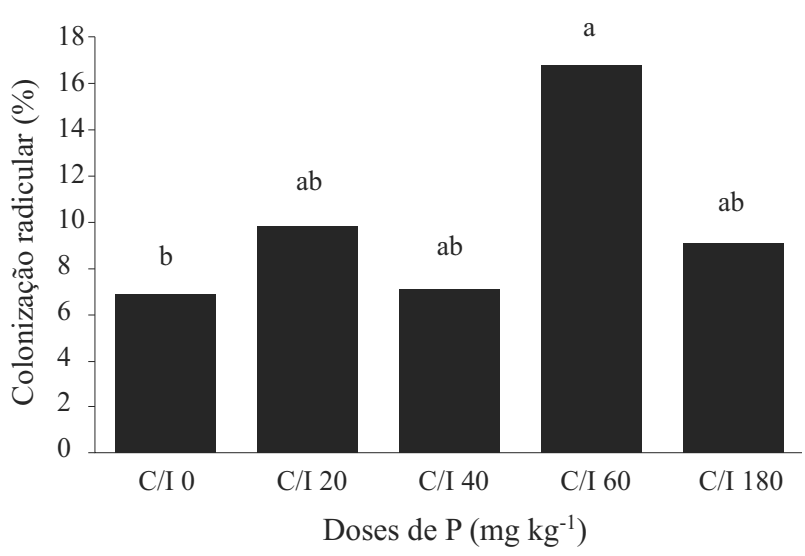

Figura 3 - Colonização micorrízica de plantas de amendoim cultivar RUNNER IAC 886, inoculadas com FMA nativos sob cinco doses de P. Média de 5 repetições. Teste de Tukey a 5\% endófito causa no crescimento de sua planta hospedeira. Em algumas plantas, taxas tão baixas como 5\% já foram suficientes para um bom desenvolvimento (KARANIKA et al., 2008). Além do que ela pode ser afetada por inúmeros fatores como a espécie vegetal, a idade da planta, densidade de raízes, dos propágulos de FMA no solo, $\mathrm{pH}$, concentração de nutrientes no solo, especialmente alta disponibilidade de $\mathrm{P}$, manejo do solo, entre outros (MCGONIGLE, 2001). Entretanto, em situações de alta disponibilidade de nutrientes, especialmente de $\mathrm{P}$, as plantas tendem a diminuir a colonização (BALOTA et al., 2010; MOREIRA-SOUZA; CARDOSO, 2002; NOGUEIRA; CARDOSO 2000).

A dependência micorrízica (DM) calculada com base na massa seca total foi variável nas diferentes doses de $\mathrm{P}$, o maior valor de DM foi verificada na dose $60 \mathrm{mg} \mathrm{kg}^{-1}$ de $\mathrm{P}(245 \%)$. Todavia nas doses 20 e $180 \mathrm{mg} \mathrm{kg}^{-1}$ de P não ocorreu DM (FIG. 4). A dependência micorrízica de uma planta pode variar com a espécie de fungo inoculada; para uma mesma planta, pode variar também desde negativa (quando não ocorre dependência da planta a micorrização) até altamente positiva (JANOS, 2007; ROCHA et al., 2006; SIEVERDING, 1991).

Recentemente, um estudo verificando o efeito dos FMA em culturas oleaginosas em casa de vegetação, demonstrou que não houve DM na adição de 120 e $240 \mathrm{mg} \mathrm{kg}^{-1}$ de $\mathrm{P}$ para plantas de amendoim e na dose $120 \mathrm{mg} \mathrm{kg}^{-1}$ de $\mathrm{P}$ para o girassol, enquanto plantas de mamona responderam a todas as doses de $\mathrm{P}$ adicionadas ao solo (BALOTA et al., 2010).

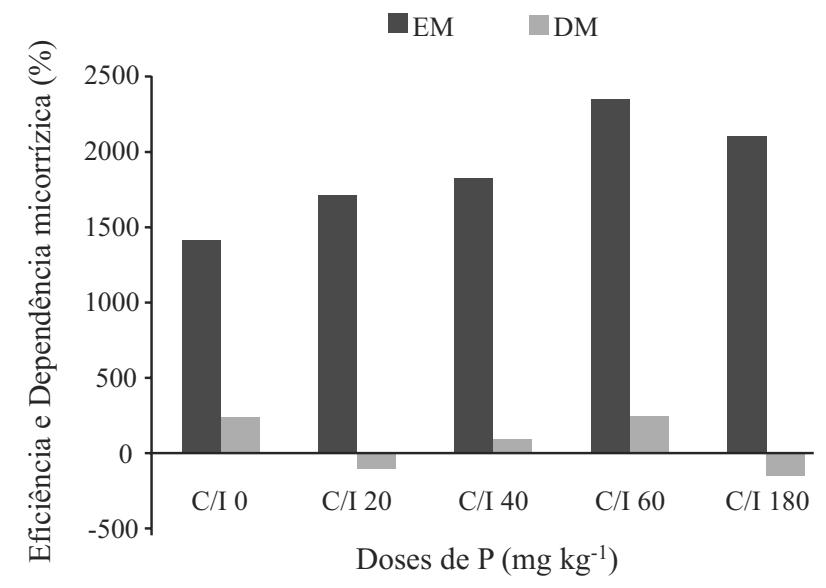

Figura 4 - Eficiência (EM) e Dependência micorrízica (DM) na produção de massa seca de plantas micorrizadas de Arachis hypogea sobre cinco doses de $\mathrm{P}$ 
Verificou-se que os FMA nativos nas cinco doses de $\mathrm{P}$ apresentaram eficiência micorrízica (EM) e a dose $60 \mathrm{mg} \mathrm{kg}^{-1}$ de $\mathrm{P}$ destacou-se das demais (FIG. 4). Diversos trabalhos verificaram que plantas inoculadas com diferentes FMA apresentaram maiores valores de eficiência micorrízica do que as plantas não inoculadas (CHAVES; BORGES, 2005; MOREIRA-SOUZA; CARDOSO, 2002).

\section{Conclusões}

1. As doses crescentes de adubação fosfatada promoveram aumento no desenvolvimento das plantas de amendoim, independente da inoculação com os FMA;

2. Os FMA nativos promoveram produção máxima de massa seca total do amendoim com doses de $114,0 \mathrm{mg} \mathrm{kg}^{-1}$ de P;

3. A colonização radicular e eficiência micorrízica foram maiores na dose $60 \mathrm{mg} \mathrm{kg}^{-1}$ de $\mathrm{P}$.

\section{Agradecimentos}

M. Moreira agradece a Fundação de Amparo a Pesquisa do Estado de São Paulo (FAPESP) pelo auxílio financeiro (no. 2006/03660-8) e pela bolsa de iniciação científica (no. 2008/56785-8) concedida ao primeiro autor. Agradecemos também a Empresa Dori Alimentos pela doação das sementes de amendoim e a Maria Alice Mascarenhas pelo auxílio técnico.

\section{Referências}

AGUIAR, R. L. F. et al. Interação entre fungos micorrízicos arbusculares e fósforo no desenvolvimento da algaroba (Prosopis juliflora (Sw) DC). Revista Árvore, v. 28, n. 04, p. 589-598, 2004.

BALOTA, E. L. et al. Efeito dos fungos micorrízicos arbusculares em culturas oleaginosas. In: CONGRESSO BRASILEIRO DE MAMONA, 4.; SIMPÓSIO INTERNACIONAL DE OLEAGINOSAS ENERGÉTICAS, 1., João Pessoa. Anais... Campina Grande: EMBRAPA Algodão, 2010. p. 680-684.

BRESSAN, W. et al. Fungos micorrízicos e fósforo, no crescimento, nos teores de nutrientes e na produção do sorgo e soja consorciados. Pesquisa Agropecuária Brasileira, v. 36, n. 02, p. 315-323, 2001.

CARNEIRO, M. A. C et al. Fósforo e inoculação com fungos micorrízicos arbusculares no estabelecimento de mudas de embaúba (Cecropia pachystachya Trec). Pesquisa Agropecuária Tropical, v. 03, n. 34, p. 119-125, 2004.
CHAVES, L. F. C.; BORGES, R. C. G. Eficiência micorrízica na produção de mudas de jacarandá-da-bahia cultivada em diferentes doses de fósforo. Acta Scientarium Agronomical, v. 27, n. 04, p. 587-594, 2005.

COSTA, C. M. C. et al. Fungos micorrízicos arbusculares e adubação fosfatada em mudas de mangabeira. Pesquisa Agropecuária Brasileira, v. 40, n. 03, p. 225-232, 2005.

DAFT, M. J. The influence of mixed inocula on endomycorrhizal development. Plant and Soil, v. 71, p.331337, 1983.

EMPRESA BRASILEIRA DE PESQUISA AGROPECUÁRIA (EMBRAPA). Centro Nacional e Pesquisa em Solos. Sistema Brasileiro de Classificação de Solos. Brasilia: EMBRAPA/SPI; Rio de Janeiro: EMBRAPA Solos, 2006. 306 p.

GIOVANETTI, M.; MOSSE, B. An evaluation of techniques to measure vesicular arbuscular mycorhizal infection roots. New Phytologist, v. 84, n. 03, p. 489-500, 1980.

HAYMAN, D. S. Practical aspects of vesicular-arbuscular mycorrhiza. In: SUBBA RAO, N. S. (Ed.). Advances in agricultural microbiology. London: Butterworth-Heinemann, 1982. p. $325-373$.

JANOS, D. P. Plant responsiveness to mycorrhizas differs from dependence upon mycorrhizas. Mycorrhiza, v. 17, n. 02, p. 75-91, 2007.

KARANIKA, E. D. et al. Arbuscular mycorrhizal fungi in Northern Greece and influence of soil resources on their colonization. Pedobiologia, v. 51, n. 06, p. 409-418, 2008.

LAMBERT, D. H. et al. Adaptation of vesicular-arbuscular mycorrhizae to edaphic factors. New Phytologist, v. 85, n. 04, p. $513-520,1980$.

MCGONIGLE, T. P. On the use of non-linear regression with the logistic equation for changes with time of percentage root length colonized by arbuscular mycorrhizal fungi. Mycorrhiza, v. 10, n. 05, p.249-254, 2001.

MEHROTA, V. S. Mycorrhizas: role and applications. New Delhi: Allied Publishers, 2005.

MOREIRA, M. et al. Sporulation and diversity of arbuscular mycorrhizal fungi in Brazil Pine in the field and in the greenhouse. Mycorrhiza, v. 17, n. 06, p. 519-526, 2007.

MOREIRA-SOUZA, M.; CARDOSO, E. J. B. N. Dependência micorrízica de Araucaria angustifolia (Bert.) O. KTZE. sob doses de fósforo. Revista Brasileira de Ciência do Solo, v. 26, n. 04, p. 905-912, 2002.

NOGUEIRA, M. A.; CARDOSO, E. J. B. N. Produção de micélio externo por fungos micorrízicos arbusculares e crescimento da soja em função de doses de fósforo. Revista Brasileira de Ciência do Solo, v. 24, n. 02, p. 329-338, 2000.

PHILLIPS, J. M.; HAYMAN, D. S. Improved procedures for cleaning roots and staining parasitic and vesicular arbuscular mycorhizal fungi for rapid assessment for infection. British Mycological Society Transactions, v. 55, n. 01, p. 158-161, 1970. 
PLENCHETTE, C. et al. Growth responses of several plant species to mycorrhizae in a soil of moderate P-fertility. Plant and Soil, v. 70, n. 02, p. 199-209, 1983.

QUAGgio, J. A.; GODOY, I. J. Amendoim. In : RAIJ, B. et al. Recomendações de adubação e calagem para o Estado de São Paulo. Campinas: IAC, 1996. 192 p. (Boletim Técnico, 100).

ROCHA, F. S. et al. Dependência e resposta de mudas de cedro a fungos micorrízicos arbusculares. Pesquisa Agropecuária Brasileira, v. 41, n. 01, p.77-84, 2006.
SENA, J. O. A. et al. Caracterização fisiológica da redução de crescimento de mudas de citros micorrizadas em altas doses de fósforo. Revista Brasileira de Ciência do Solo, v. 28, n. 05, p. 827-832, 2004.

SIEVERDING, E. Vesicular-arbuscular mycorrhiza manament in tropical agrosystems. Eschborn: Deutsche Gesellschaft fü Technische Zusammenarbeit, 1991.

SMITH, S. E. et al. Mycorrhizal fungi can dominate phosphate supply to plants irrespective of growth responses. Plant physiology, v. 133, n. 01, p. 16-20, 2003. 